\begin{tabular}{|c|c|c|c|}
\hline \multirow{3}{*}{$\begin{array}{r}\text { Case Reports in } \\
\text { Gastroenterology }\end{array}$} & \multicolumn{2}{|c|}{ Case Rep Gastroenterol 2017;11:72-77 } & \multirow[b]{2}{*}{$\begin{array}{l}\text { Karger } \\
\text { Open access }\end{array}$} \\
\hline & $\begin{array}{l}\text { DOI: 10.1159/000456606 } \\
\text { Publisned online: February 28, } 2017\end{array}$ & $\begin{array}{l}\text { (c) } 2017 \text { The Author(s)Published by S. } \\
\text { Karger AG, Basel } \\
\text { www.karger.com/crg }\end{array}$ & \\
\hline & $\begin{array}{l}\text { This article is licensed under the } \\
\text { International License (CC BY-NC) } \\
\text { Usage and distribution for commerci }\end{array}$ & $\begin{array}{l}\text { nons Attribution-NonCommercial } 4.0 \\
\text { ger.com/Services/OpenAccessLicense) } \\
\text { uires written permission. }\end{array}$ & \\
\hline
\end{tabular}

\title{
Therapeutic Interventional Endoscopic Ultrasound Based on Rare Cases in Indonesia: A Single-Center Experience in Unselected Patients
}

\author{
Cosmas Rinaldi A. Lesmana ${ }^{a, b}$ Rino A. Gani ${ }^{b}$ Irsan Hasan ${ }^{b}$ \\ Andri Sanityoso Sulaiman ${ }^{b}$ Laurentius A. Lesmana ${ }^{a}$ \\ ${ }^{a}$ Digestive Disease \& GI Oncology Center, Medistra Hospital, Jakarta, Indonesia; \\ ${ }^{b}$ Department of Medicine, Hepatobiliary Division, Cipto Mangunkusumo Hospital, \\ Universitas Indonesia, Jakarta, Indonesia
}

\section{Keywords}

Therapeutic interventional endoscopic ultrasound · Gastroenterology practice $\cdot$ Indonesia

\begin{abstract}
Background: Endoscopic ultrasound (EUS) is still not widely available and has a barrier in most Southeast Asian countries due to lack of training program, high cost, and hospital investment. In this study, we would like to show the impact of therapeutic interventional EUS procedures in gastroenterology practice in Indonesia, which represents the biggest Southeast Asian country. Methods: Patients who underwent interventional EUS procedure in Medistra Hospital were prospectively recruited within 1 year. Results: Of 147 patients who underwent EUS procedures, 39 patients underwent fine needle aspiration. Most of the cases suffered from pancreatic cancer $(47.5 \%)$ followed by ampullary cancer $(20 \%)$, gastric subepithelial mass $(10 \%)$, and other conditions. There were 4 rare cases that underwent therapeutic interventional EUS procedures. Patients with large mesenteric cyst attached to the gastric wall and large left liver lobe cyst with gastric compression who were previously suspected with gastrointestinal stromal tumor were successfully managed by cyst aspiration. One patient with a large pseudocyst due to chronic pancreatitis was successfully managed by plastic
\end{abstract}




\section{Case Reports in Gastroenterology}

Case Rep Gastroenterol 2017;11:72-77 DOI: $10.1159 / 000456606$ (c) 2017 T1 www.karger.com/crg

Lesmana et al:: Therapeutic Interventional Endoscopic Ultrasound Based on Rare Cases in Indonesia: A Single-Center Experience in Unselected Patients

stent placement. Another patient with duodenal duplication cyst causing duodenal obstruction was managed by inserting a plastic stent through the cyst. No complications were observed during and after the therapeutic EUS procedures. Conclusions: Innovation in interventional EUS has a high impact in gastroenterology practice as well as in a developing country like Indonesia, which represents the biggest Southeast Asian country. Further developments are needed regarding the cost, investment, and especially the necessary training curriculum to make this technology available in tertiary referral centers.

(C) 2017 The Author(s)

Published by S. Karger AG, Basel

\section{Background}

Endoscopic ultrasound (EUS) has been shown to be a highly favorable diagnostic and therapeutic development in Western countries as well as in some developed Asian countries. In most Southeast Asian countries including Indonesia, EUS development is still in its infancy and encounters many barriers related to the lack of proper training facilities, expensive hospital investment, insurance coverage, and high procedural cost [1].

The development of therapeutic interventional EUS has replaced some surgical procedures such as EUS-guided biliary drainage, EUS-guided stenting of pancreatic pseudocysts, and EUS radiofrequency ablation for preventing recurrent liver cyst or pancreatic cancer [24]. In the field of hepatology, EUS has also given a new paradigm in managing patients with gastric varices in liver cirrhosis through so-called EUS-guided vascular intervention [5]. However, in view of high costs and lack of expertise, most gastroenterologists would still prefer to refer such patients to surgeons. However, some surgical procedures such as pancreaticoduodenectomy require a high-experience center, which might not be available in most Asian developing countries.

Therefore, to illustrate the availability of suitable patients for EUS procedures and to report the impact of therapeutic interventional EUS procedures in unselected patients, we like to report a rare case series in a private referral hospital to document the need for therapeutic EUS facilities also in a developing country.

\section{Materials and Methods}

Patients who underwent therapeutic interventional EUS procedures were recruited from the EUS hospital database. The therapeutic interventional EUS procedures were performed by a consultant gastroenterologist experienced in advanced therapeutic endoscopic procedures including endoscopic retrograde cholangiopancreatography (ERCP), interventional transabdominal ultrasound procedures, and EUS-fine needle aspiration (FNA) procedures. The procedures were supervised by a senior consultant experienced in interventional gastroenterology procedures. The EUS equipment was an Olympus JF UCT 180 EUS scope which was connected to an Aloka IPF-1701C ultrasound machine (Tokyo, Japan). The EUS needles used were Olympus 19-G aspiration needle NA-200H-8022 and the EUS Boston 19-G aspiration needle 17462614. The guide wire was a 0.35-inch Tracer Metro Direct Wire Guide (METII-35-480/Wilson Cook). Double pigtail stents were used (7-Fr Zimmon Biliary Stent). 


\section{Case Reports in Gastroenterology}

Case Rep Gastroenterol 2017;11:72-77

DOI: $10.1159 / 000456606$

(c) 2017 Th

www.karger.com/crg

Lesmana et al.: Therapeutic Interventional Endoscopic Ultrasound Based on Rare Cases in Indonesia: A Single-Center Experience in Unselected Patients

\section{Results}

Of 147 patients who underwent EUS procedures from the hospital database, 39 patients (20 males and 19 females) underwent EUS-FNA procedures and 4 of them underwent therapeutic interventional EUS procedures. Based on the EUS-FNA database, pancreatic malignancy ( $47.5 \%)$ was the most common etiology of the diseases followed by ampullary cancer (20\%), gastric subepithelial mass (10\%), intraductal papillary mucinous neoplasm (5\%), benign pancreatic cyst (5\%), large intra-abdominal cyst attached to the gastric wall, large left liver lobe cyst compressing the gastric wall, duodenal duplication cyst (DDC) with chronic recurrent pancreatitis, and distal common bile duct mass.

Therapeutic interventional EUS procedures were successfully performed in 4 rare cases without complications. The first case was a 26-year-old female referred from another hospital with incidental finding of a large intra-abdominal cyst suspected of a giant pancreatic pseudocyst, which was located between the gastric wall and the corpus to tail area of the pancreas based on the abdominal CT scan. The patient previously underwent evaluation for history of chronic hepatitis B infection. Transabdominal ultrasound found an incidental cyst and therefore, the patient was suggested to undergo abdominal CT scan examination. However, the patient did not have any history of pancreatitis or a history of alcohol consumption. Cyst aspiration was done (Fig. 1) and the result of the fluid analysis corresponded to a benign cyst. Then the patient underwent surgery because of recurrent cyst and was shown to have a benign solitary mesenteric cyst. After operation, there was no further recurrence.

The second case was a 63-year-old female who was referred from another hospital with abdominal fullness because of compression of the gastric wall due to a large submucosal mass suggestive of a gastrointestinal stromal tumor based on upper gastrointestinal endoscopy examination. EUS examination revealed a large liver cyst in the left liver lobe just beside the heart, which compressed the gastric wall. Cyst aspiration was successfully done without complication.

The third case was a 37-year-old male referred from another hospital with a history of heavy alcohol consumption, abdominal pain and distention, and recurrent pancreatitis during the last months. The amylase and lipase blood levels before procedure were 823 and 1,892 U/L. EUS examination revealed pancreatic alterations compatible with chronic pancreatitis with a large pancreatic pseudocyst compressing the gastric wall. A 7-Fr double pigtail stent was placed into the pseudocyst under EUS guidance (Fig. 2). After 1 month, the cyst had resolved and after 3 months, the stent was removed. His last amylase and lipase blood levels were 22 and $40 \mathrm{U} / \mathrm{L}$. His clinical condition came back to normal and the patient remained free of pancreatitis attacks.

The last case was a 20-year-old male referred from another hospital with recurrent abdominal pain due to recurrent pancreatitis. Amylase and lipase were 145 and 1,008 U/L, respectively, and the CA $19-9$ was $3.41 \mathrm{U} / \mathrm{mL}$. Based on the abdominal CT scan, there was a large hypodense mass with a diameter of $55 \times 44 \times 72 \mathrm{~mm}$ at the head of the pancreas area suggestive of a cystadenoma. EUS examination revealed a bulging cyst at the postpyloric area compressing and obstructing the inside of the duodenal cavity suggestive of a picture of DDC. This finding was compatible with the abdominal CT scan examination. The cyst was suspected to be due to a lot of the preserve inside the cyst cavity (Fig. 3). The patient and the family were advised to undergo surgery, but the family refused. Then, a 7-Fr double pigtail stent was placed into the cyst cavity. The amylase and lipase from the cyst fluid analysis were 27,016 and 115,450 U/L, respectively. The culture from the cyst fluid revealed Klebsiella pneumoniae, which was treated by meropenem. One month after the procedure, the cyst 


\section{Case Reports in Gastroenterology}

Case Rep Gastroenterol 2017;11:72-77 DOI: $10.1159 / 000456606$ (c) 2017 www.karger.com/crg

Lesmana et al.: Therapeutic Interventional Endoscopic Ultrasound Based on Rare Cases in Indonesia: A Single-Center Experience in Unselected Patients

had resolved and there were no further recurrent attacks of pancreatitis. His last amylase and lipase values were 51 and $86 \mathrm{U} / \mathrm{L}$.

\section{Discussion}

To our knowledge, this is the first study in Indonesia, which represents the biggest Southeast Asian country, to document the usefulness of diagnostic EUS and therapeutic interventional EUS in gastroenterology practice. The study indicates that the indications for the procedure mimic those in Western countries and draw attention to rare findings. The development of EUS procedures in most Southeast Asian country is still questioned and is hampered because of lack of training facilities, necessity of hospital investment, and high cost.

The purpose of this study was to show the major impact of therapeutic interventional EUS procedures in difficult and rare cases in gastroenterology practice because EUS development is still lacking in most Asian developing countries. This study confirms that the role of EUS procedure in pancreatic cysts or pseudocysts is superior to other imaging studies (transabdominal ultrasound, abdominal CT scan, and abdominal MRI) [6]. The advantage of EUS procedure is the possibility for cyst aspiration for fluid analysis; this can be combined with therapeutic interventions such as stenting for drainage [7]. Another common therapeutic EUS procedure is EUS-guided biliary drainage when ERCP has failed in common bile duct cannulation and stenting [8].

Surgical intervention remains possible for internal and external drainage, especially in complicated cases with infected pseudocyst, pancreatic duct stricture, bile duct stenosis, and perforation. Even though a randomized controlled trial has shown that there were no differences in the success rate, complications, and re-intervention between surgery and endoscopic drainage, however, the right time for surgical action, the need of resection (partial leftsided pancreatectomy or Whipple's procedure), and the surgeon's experience remain major issues not only among the physicians and surgeons, but also for the patient and his family [9, 10].

The first two cases described above show that simple cyst aspiration could solve the problem without the need for immediate surgery even though long-term follow-up is needed in case of possible recurrent cyst. Increasingly, surgical avoidance has become the preferred therapy for whenever there is no suspicion or evidence of malignancy.

The other two rare cases (large pancreatic pseudocyst and DDC) were also successfully managed by therapeutic interventional EUS. Follow-up again is necessary to find out whether therapeutic EUS was the final solution or whether additional surgery by an experienced team will be advisable $[11,12]$.

This study has given important messages for the gastroenterological practice in Indonesia by showing that EUS procedures have an important role in managing some difficult cases in daily practice. However, these procedures require high skill and experience and the presence of a high-quality multidisciplinary team capable of handling potential complications inherent to the endoscopic procedure itself. 


\section{Conclusions}

Therapeutic interventional EUS has a high impact in gastroenterological practice also in developing countries such as Indonesia, which represents the largest country in Southeast Asia. The development of EUS procedures in most developing countries is mandatory but requires considerable expenses with regard to the cost, equipment investment, and especially adequate training facilities.

\section{Acknowledgement}

We thank Prof. Guido N. Tytgat from AMC, the Netherlands, for his criticism and advice for the manuscript.

\section{Statement of Ethics}

All patients who underwent therapeutic EUS procedures have been informed and given consent for the publication of the procedures and images. This study has been approved by the hospital's ethics committee (IRB approved).

\section{Disclosure Statement}

Cosmas Rinaldi A. Lesmana, Rino A. Gani, Irsan Hasan, Andri Sanityoso Sulaiman, and Laurentius A. Lesmana declare that they have no conflict of interest.

\section{References}

1 Lesmana CRA, Ho KY, Lesmana LA: Impact of endoscopic ultrasound procedures in various pancreatobiliary disorders in Indonesia based on a case series in a private hospital. Case Rep Gastroenterol 2015;9:206-214. Cheriyan D, Obando JV: Therapeutic endoscopic ultrasound. Gastroenterol Hepatol 2015;11:467-473. Tarantino I, Barresi L: Interventional endoscopic ultrasound: therapeutic capability and potential. World J Gastrointest Endosc 2009;1:39-44.

4 Iwashita T, Doi S, Yasuda I: Endoscopic ultrasound-guided biliary drainage: a review. Clin J Gastroenterol 2014;7:94-102.

5 Sexena P, Lakhtakia S: Endoscopic ultrasound guided vascular access and therapy. Endosc Ultrasound 2015;4:168-175.

6 Larghia A, Petroneb MC, Galassoa D, et al: Endoscopic ultrasound in the evaluation of pancreatobiliary disorders. Dig Liver Dis 2010;42:6-15.

7 Aghdassi AA, Mayerle J, Kraft M, et al: Pancreatic pseudocyst - when and how to treat? HPB 2006;8:432-441.

8 Dhir V, Artifon ELA, Gupta K, et al: Multicenter study on endoscopic ultrasound-guided expandable biliary metal stent placement: choice of access route, direction of stent insertion, and drainage route. Dig Endosc 2014;26:430-435.

-9 Varadarajulu S, Bang JY, Sutton BS, et al: Equal efficacy of endoscopic and surgical cystogastrostomy for pancreatic pseudocyst drainage in a randomized trial. Gastroenterol 2013;145:583-590. Gouma DJ: Stent versus surgery. HPB 2007;9:408-413.

-11 Uzun MA, Koksal N, Kayahan M, et al: A rare case of duodenal duplication treated surgically. World J Gastroenterol 2009;15:882-884.

12 Kurien RT, Chowdhury SD, Unnikrishnan LS, et al: Endoscopic treatment of a duodenal duplication cyst. Endoscopy 2014;46:E583-E584. 


\section{Case Reports in Gastroenterology \\ Lesmana et al:: Therapeutic Interventional Endoscopic Ultrasound Based on Rare Cases in Indonesia: A Single-Center Experience in Unselected Patients}
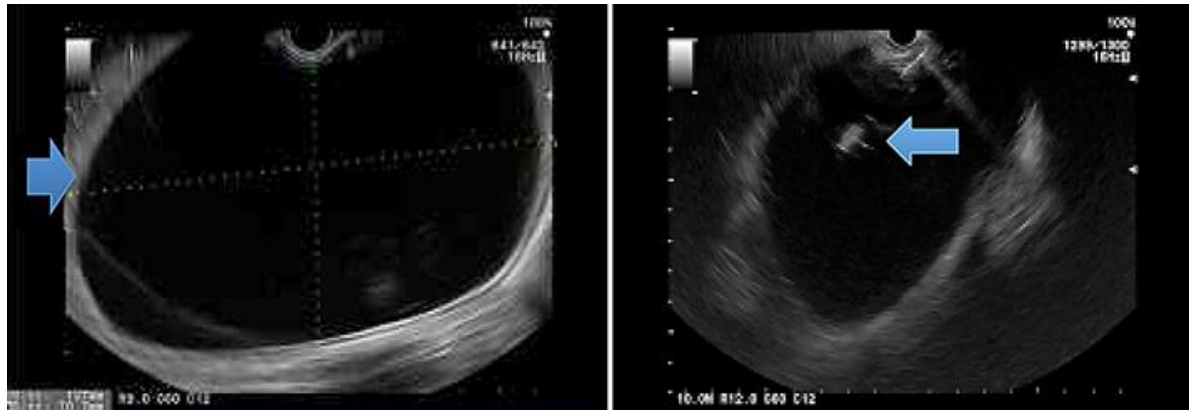

Fig. 1. A large intra-abdominal benign mesenteric cyst successfully managed by aspiration needle through EUS procedure.
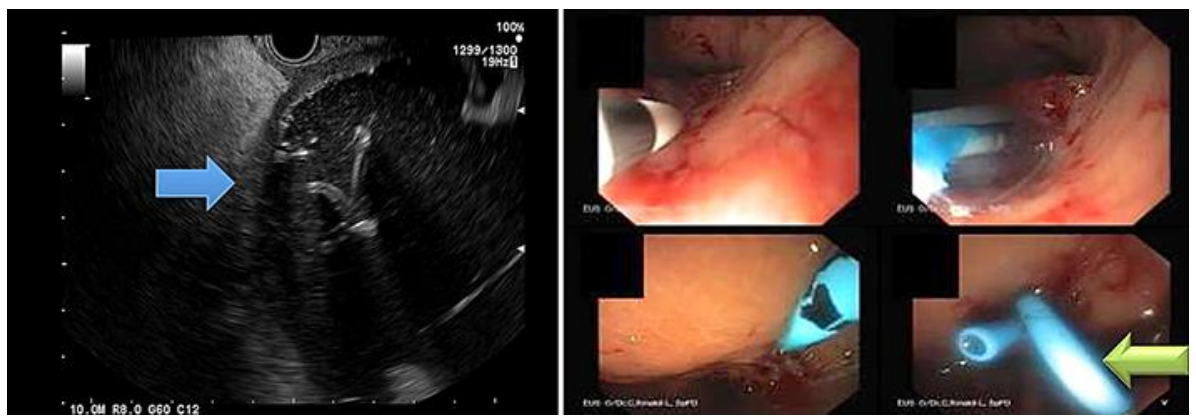

Fig. 2. A large infected pancreatic pseudocyst successfully managed by 7-Fr double pigtail stent.
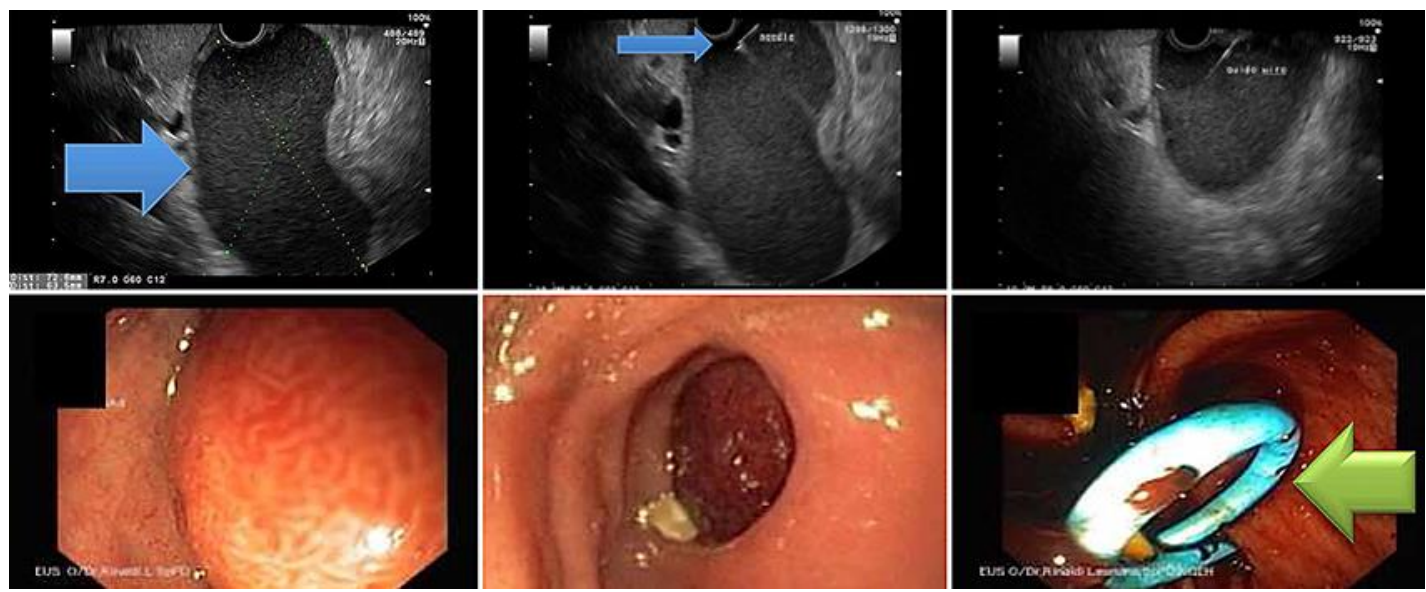

Fig. 3. Duodenal duplication cyst with duodenal obstruction successfully managed by 7-Fr double pigtail stent. 